\title{
The 1976-77 Climate ShIFT OF THE PACIFIC OCEAN
}

By Arthur J. Miller, Daniel R. Cayan, Tim P. Barnett, Nicholas E. Graham and Josef M. Oberhuber

$\mathrm{U}$ nderstanding how climate varies in time is a central issue of climate research. Of particular interest are climate variations which occur within the human lifespan, say over 5- to 100-y time scales. Climate changes might occur as a gradual drift to a new state, a series of long-term swings, or a sequence of abrupt steps. The climate record over the last 100 years or so exhibits ample evidence for all these types of variations (Jones et al., 1986), but we have little understanding of what causes and controls these regime changes (Karl, 1988; Wunsch, 1992). Though many of these variations in climate are certainly natural, some components could be associated with increased concentrations of greenhouse gases or other anthropogenic effects. To advance our understanding of mankind's potential influence on climate, the study of various natural climate variations is of paramount importance.

During the 1976-77 winter season, the atmosphere-ocean climate system over the North Pacific Ocean was observed to shift its basic state abruptly (e.g., Graham, 1994). The Aleutian Low deepened (Fig. 1a) causing the storm tracks to shift southward and to increase storm intensity. Downstream, over the continent of North America, warmer temperatures occurred in the northwest (Folland and Parker, 1990), decreased storminess was observed in the southeastern U.S. (Trenberth and Hurrell, 1993), and diminished precipitation and streamflow in the western U.S. (Cayan and Peterson, 1989). In the ocean, sea surface temperature (SST) cooled in the central Pacific and warmed off the coast of western North America (Fig. 1c). These major changes in the physical climate were accompanied by equally impressive changes in the biota of the Pacific basin (Venrick et al., 1987; Polovina et al., 1994). This remarkable climate transition was illustrated by Ebbesmeyer et al. (1991) in a composite

A.J. Miller, D.R. Cayan, T.P. Barnett and N.E. Graham, Scripps Institution of Oceanography, La Jolla, CA 920930224, USA. J.M. Oberhuber, Meteorological Institute, University of Hamburg, 2000 Hamburg 13, FRG. time series of 40 environmental variables (Fig. 2). Each of the 40 time series were normalized by their standard deviation, then averaged together to form a single time series, which suggests that a step-like shift occurred in the winter of 1976-77. The North Pacific climate system fluctuated around this perturbed state for roughly 10 years thereafter (Trenberth, 1990).

It has been suggested independently by several investigators that the '76-' 77 shift was caused by remote forcing from the tropical Pacific Ocean, where a contemporaneous warming of SST occurred, via well-known atmospheric teleconnections to the midlatitudes (Graham, 1994). Recent numerical experiments using atmospheric models forced by observed tropical SST anomalies support this hypothesis (Kitoh, 1993; Graham et al., 1994). The influence of the midlatitude ocean on the '76-'77 shift is thought to be secondary, perhaps in the maintenance (persistence) of the anomalous atmospheric state through ocean-to-atmosphere feedback mechanisms (e.g., Miller, 1992). The numerical results presented in this study were designed to test the idea that the midlatitude oceanic component of the '76-'77 climate shift was predominantly forced by the atmosphere.

\section{Isopycnic Ocean Model with Surface Mixed Layer}

We have been able to simulate the oceanic component of the '76-'77 climate shift with a sophisticated ocean general circulation model forced by observed monthly mean anomalies of total surface heat fluxes and surface wind stress (Miller et al., 1994). The ocean model (Oberhuber, 1993), set in Pacific basin-wide geometry with realistic topography, consists of nine vertical layers with open-ocean horizontal resolution of about $450 \mathrm{~km}$. The top layer of the model represents the turbulent mixed layer at the ocean surface in which atmospheric processes (wind stresses and surface heat fluxes) directly force the model. The eight layers below the mixed layer have constant density but variable thickness, tem-
. . . the atmosphere-

ocean climate system over the North Pacific Ocean was observed to shift its basic state abruptly ... 
$\triangle$ SLP - OBSERVED [mb]

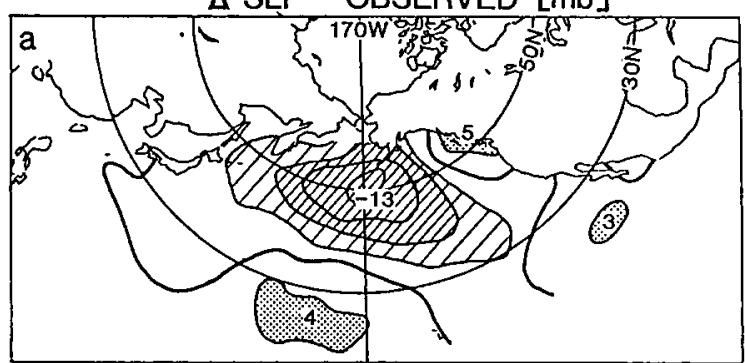

$\triangle$ HEAT FLUX - OBSERVED $\left[\mathrm{W} / \mathrm{m}^{2}\right]$

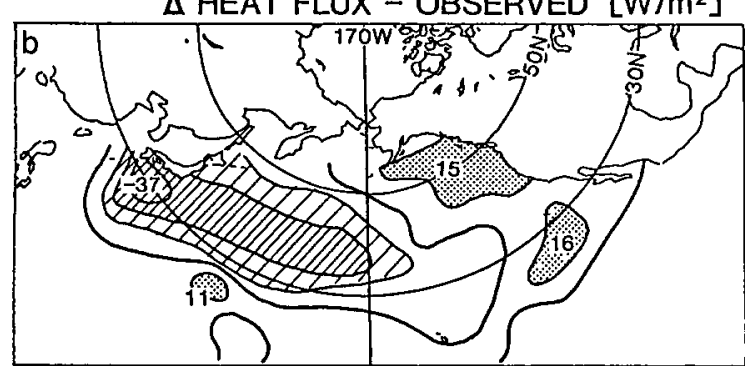

$\triangle$ SST - OBSERVED $\left[{ }^{\circ} \mathrm{C}\right]$

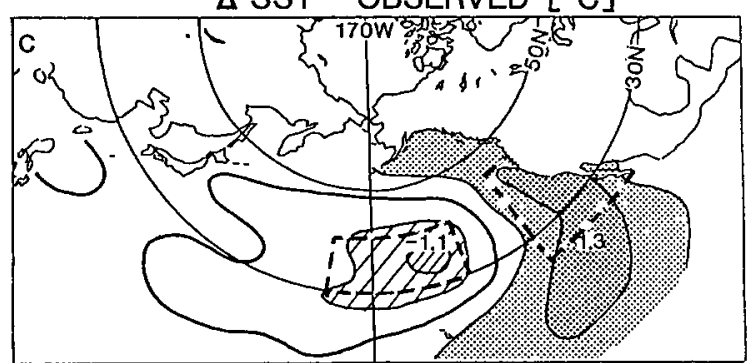

$\triangle$ SST - MODELED $\left[{ }^{\circ} \mathrm{C}\right]$

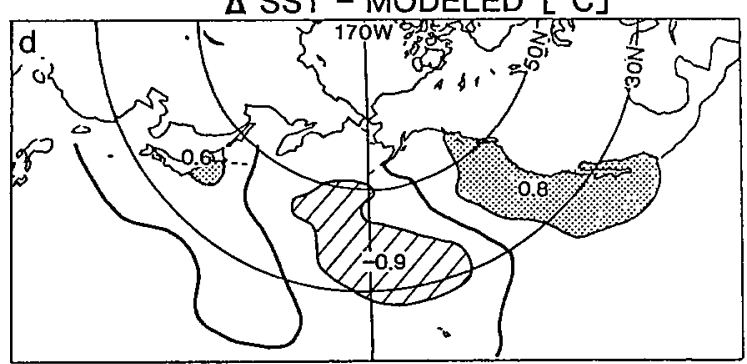

Fig. 1: Difference fields for winter conditions for the period 1976-77 through 1981-82 minus the period 1970-71 through 1975-76. Winter defined as Dec.-Jan.-Feb. (a) COADS sea-level pressure, (b) COADS surface heat flux, (c) COADS SST, (d) model-simulated SST. Mid-Pacific and California Coastal regions delineated by dashed lines in $(\boldsymbol{c})$.

perature, and salinity; these layers are insulated from the direct forcing of the atmosphere but are set in motion through dynamical/thermodynamical interaction and mass exchange with the overlying mixed layer.

To understand what controls the modeled ocean response, it is necessary to consider the heat budget of the surface mixed layer, which is

$\frac{\partial T_{s}}{\partial t}+\mathbf{u} \cdot \nabla T_{s}+\frac{w_{e}}{H}\left(T_{s}-T_{o}\right)=\frac{Q}{\rho c_{p} H}+K \nabla^{2} T_{s}$

where $T_{\mathrm{s}}$ is the SST, $\mathbf{u}$ is the horizontal current (through which wind-driven Ekman currents and

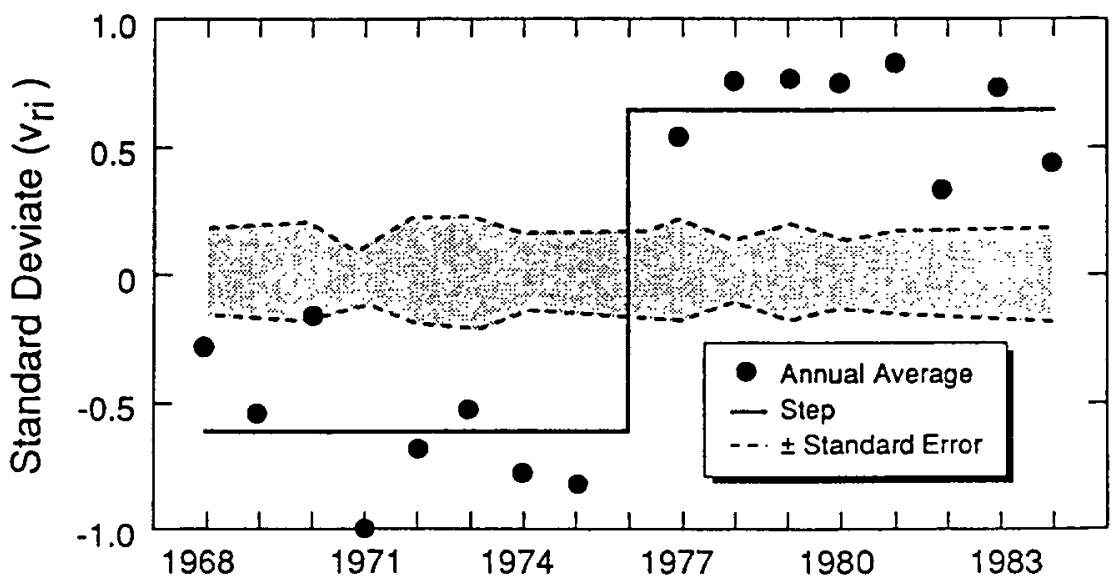

Fig. 2: Time series ( $\bullet$ ) of the mean of standardized anomalies for 40 environmental variables. Uniform step (-) has been fit to the data to illustrate the 1976-77 transition. Shaded area represents the standard error of the variables computed in each year. From Ebbesmeyer et al. (1991). surface geostrophic currents act), $w_{\mathrm{e}}$ is the entrainment velocity (which is either positive or zero and which is influenced, among many other things, by turbulent kinetic energy (TKE) input by the atmospheric wind field), $H$ is the variable mixed-layer depth, $T_{\mathrm{o}}$ is the temperature of entrained fluid (from beneath the mixed layer), $Q$ is the total surface heat flux, $c_{\mathrm{p}}$ is the specific heat of seawater, and $K$ is the spatially variable horizontal diffusivity. We refer to the terms, from left to right, as (a) the SST tendency term, (b) the horizontal advection term, (c) the vertical mixing/entrainment term, (d) the surface heat flux term and (e) the horizontal diffusion term. Equation (1) represents the physical processes of temperature change (a) in the surface mixed layer at a given location through (b) horizontal currents moving warm or cold water into or out of the location, (c) mixing (i.e., entraining) of the water beneath the mixed layer as it deepens, (d) heat exchange at the air-sea interface, due to latent, sensible, and radiative heat fluxes, and (d) horizontal eddy diffusion, which is a parameterization of unresolved processes.

The observed anomalies of the atmospheric forcing (i.e., surface heat fluxes, wind stresses, and TKE input) are added to respective mean fields, which drive the ocean to a nearly stationary seasonal cycle close to that observed (as described fully by Miller et al., 1994). The model ocean has no feedback to the anomalous fluxes which drive the system and thus is free to evolve fields such as SST according to the observed strength of the various processes which affect the surface mixedlayer heat budget. The observed heat flux forcing anomalies depend only weakly on the observed 
SST anomalies and more strongly on the difference between observed SST and observed air temperature; thus there is nothing in the design of this experiment that guarantees a "good" simulation of the observed SST anomalies.

\section{Simulated Long-Term SST Variations}

The hindcast basinwide fields of SST, surface mixed-layer depth, thermocline depth and current velocity provide a unique history of physical processes that are only sparsely sampled by observations. We have examined the variability of model SST in a variety of ways to verify the '76-'77 shift in the model and to diagnose its causes (see Cayan et al., 1994; Miller et al., 1994, for other extensive analyses). Not only is the shift well reproduced by the model (Fig. 1d), but we find strong correlation between model and observed SST on monthly and seasonal time scales as well. In areal averages of two key regions, which we have dubbed "the Mid-Pacific region" $\left(180^{\circ} \mathrm{W}-150^{\circ} \mathrm{W} ; 30^{\circ} \mathrm{N}-40^{\circ} \mathrm{N}\right)$ and "the California Coastal region" $\left(135^{\circ} \mathrm{W}-120^{\circ} \mathrm{W} ; 25^{\circ} \mathrm{N}-45^{\circ} \mathrm{N}\right)$, we find that the correlation coefficients between model and observed time series of SST anomalies are 0.67 and 0.71 , respectively.

Empirical orthogonal function (EOF) analyses help to identify large-scale patterns which occur in complicated fields. Our EOF analyses of monthlymean SST for the entire record, as well as for the individual 3-mo seasons, reveal strong comparability with observations. The wintertime EOF analysis is particularly remarkable in that the first three dominant patterns of SST variability are well reproduced by the model in both space and time
(Fig. 3). The model EOFs 1 and 2 have rather sharp transitions in the winter of 1976-77, though the observed analogues exhibit a less distinct transition. It is clear that the step-like shift that appears in individual point variables is not strongly represented by a single EOF; the evidence from the SST EOFs is not as clear-cut as the composite variables shown in Figure 2. For both the modeled and observed North Pacific SST field, the step is apparently a combination of the trend-like behavior of EOF 1 and the more abrupt mid-1970's change of EOF 2.

\section{Diagnosing the Cause of the Modeled Shift}

The heat budget of the model surface mixed layer (Eq. 1) was examined to determine the cause of the ocean shift as well as to attempt to understand why the regimes persisted before and after the shift. Towards this end, monthly means of the terms in (Eq. 1) were computed during the integration and the climatological monthly means for the 1970-1988 interval were subtracted from the archived fields to obtain anomalies. Time series of the anomalies of the individual terms of the heat budget reveal that the surface heat flux term is typically the largest anomalous forcing term, in line with results of previous studies (e.g., Luksch and von Storch, 1992). In the California Coastal region, typical anomalies of the surface heat flux term tend to be about four times larger than either the horizontal advection or entrainment terms. In contrast, the Mid-Pacific is climatologically more influenced by wind mixing because of the variable winds of the storm tracks (see Trenberth and Hurrell, 1994), so that variability of the surface heat
$T$

basinwide fields. . .

provide a unique

history of physical

processes that are

only sparsely

sampled by

observations.
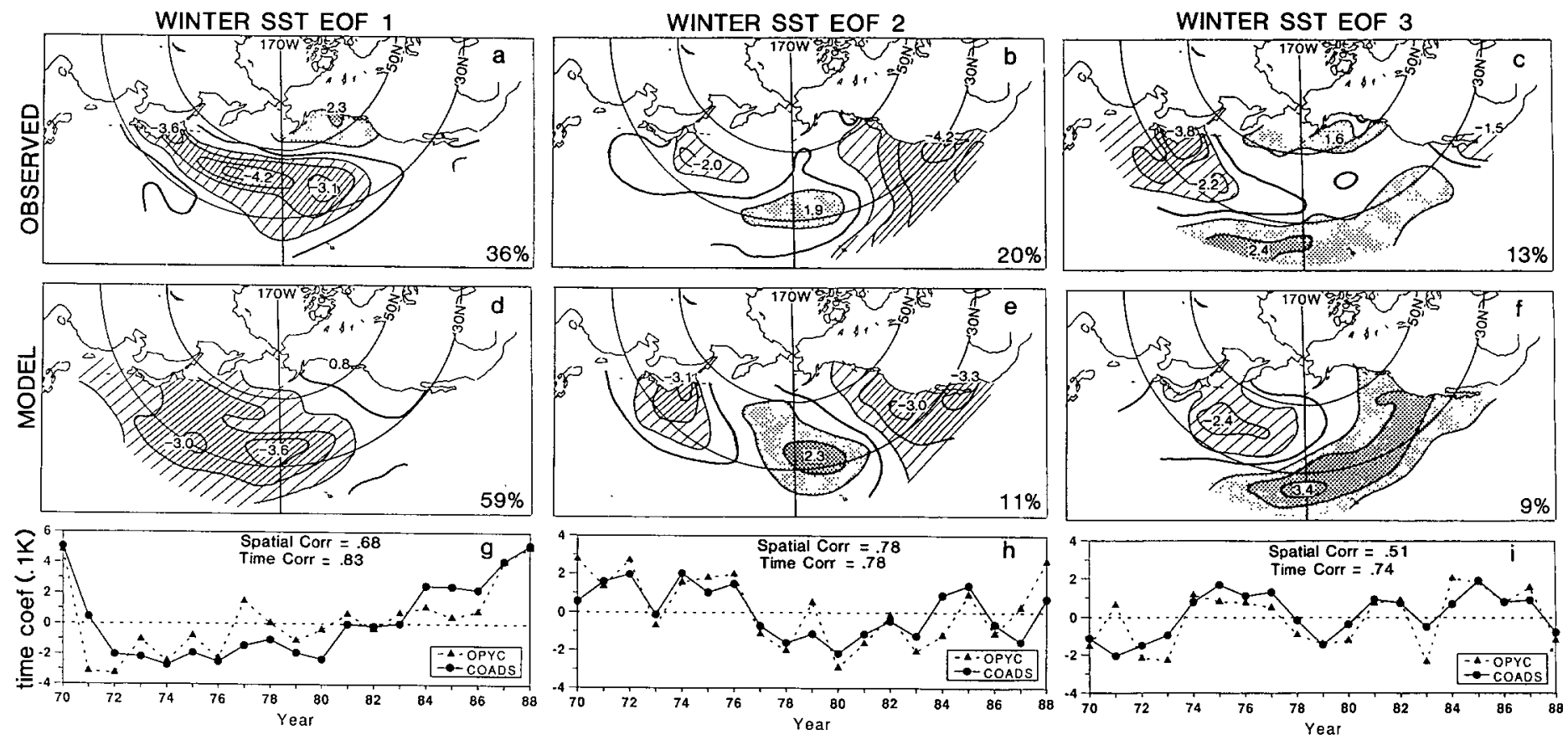

Fig. 3: EOF's of winter-season SST anomalies for the 1970-1988 time interval. (a, b, c) COADS observations, (d, e, f) model simulation, $(\boldsymbol{g}, \boldsymbol{h}, \boldsymbol{i})$ times series of EOF coefficients for Ocean isoPYCnal model (OPYC) and COADS observations. 
flux term is only twice as large as that of horizontal advection and is typically of similar amplitude to vertical mixing effects. Though only slightly weaker in effect than horizontal advection, diffusion usually acts in opposition to the heat flux with relatively passive (damping) effects on SST. Typical variations in the depth of the monthly-mean mid-Pacific winter mixed layer are 10-20 m, in reasonable accord with the North Pacific observations (Levitus, 1982).

. . both oceanic

states are maintained

. . by long-term

changes in the

strength of . . .

mixing . . .

\section{The Mid-Pacific Shift}

In the Mid-Pacific region, our model results indicate that the '76-' 77 oceanic shift was caused mainly by two effects: anomalously strong persistent cooling due to the horizontal advection term combined with sizable cooling by the surface heat flux term (Fig. 4). Thus, the large-scale ocean currents driven by the atmosphere anomalously cool the central Pacific by advecting cooler water from the North Pacific into the Mid-Pacific region, while at the same time the atmosphere draws heat from the ocean through air-sea heat exchange.

\section{Mid-Pacific Mixed Layer Heat Budget}

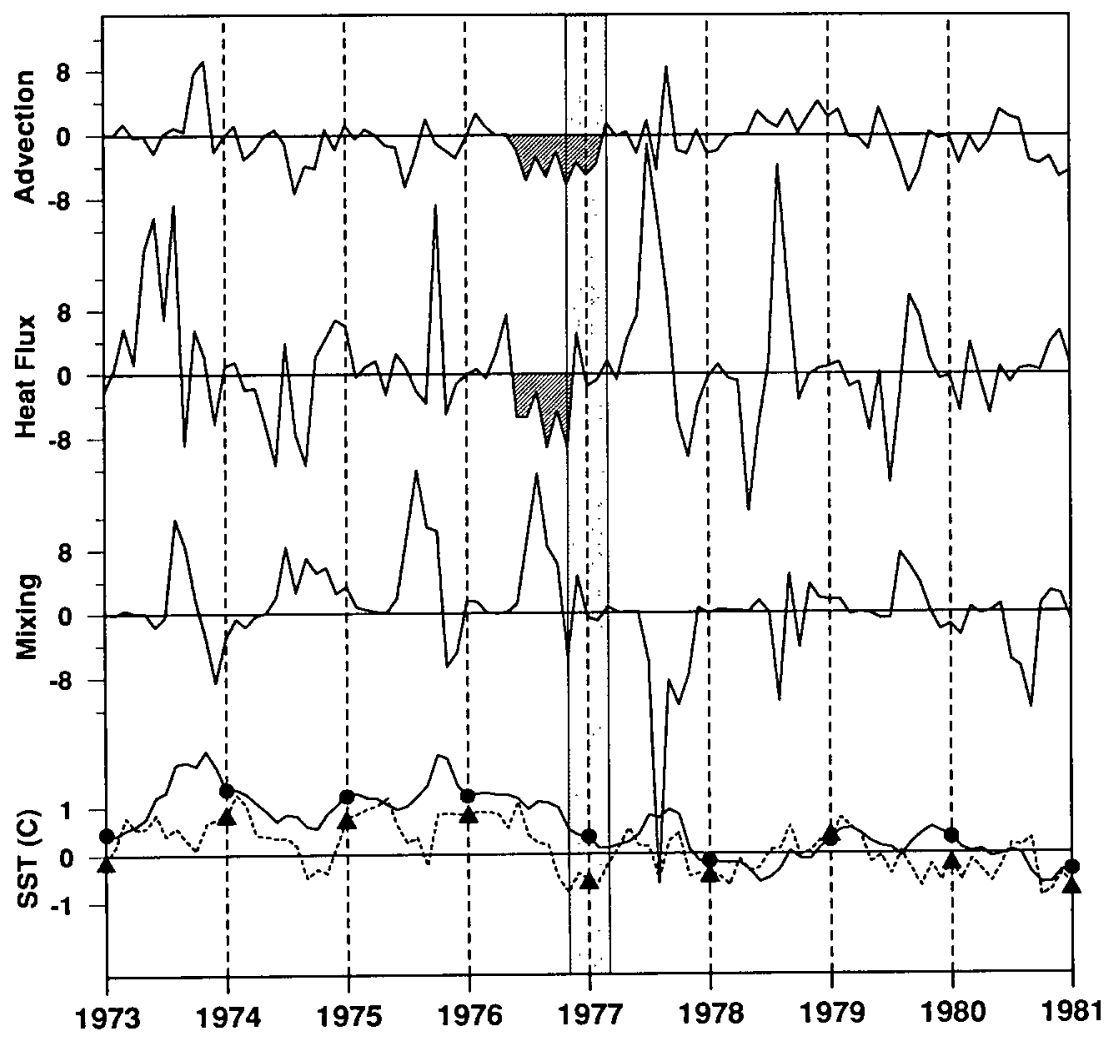

Fig. 4: Time series of monthly mean anomalies for the interval 1973-1980 in the Mid-Pacific region. Anomalies computed with respect to entire 1970-1988 interval. Three top panels show modeled terms in the mixedlayer heat budget in ${ }^{\circ} \mathrm{C} / \mathrm{s}$, scaled by $10^{s}$. Bottom panel shows winter SST anomaly for model (-) and observed (- - $\left.-\mathbf{-}_{-}\right)$. Vertical dashed lines indicate January for each year. Stippled area indicates approximate interval of the "76-'77 climate shift. Hatching indicates concurrent events of forcing in horizontal advection term and surface heat flux term, which precipitated the simulated shift.
During the $6 \mathrm{y}$ preceding the shift, the heat budget terms also tell us that an anomalously weak entrainment term served to hold the central North Pacific ocean in a shallow mixed layer, warm SST state. In the years following the shift, stronger wind mixing (TKE) helped to deepen the MidPacific mixed layer and hence to maintain the cooler Mid-Pacific that prevailed in those years. Thus, this analysis shows us that although the ocean was forced into a different state in fall/winter of $1976-77$ by an extreme atmospheric event, both oceanic states are maintained (held in their relatively persistent states) by long-term changes in the strength of the mixing/entrainment term. These changes in mixing are clearly associated with prolonged changes in the flux of atmospheric momentum to the ocean (stronger wind mixing after the shift). But they are also due to changes in the temperature of the fluid underlying the mixed layer, because the pool of cool water beneath the mixed layer can provide a thermal memory of previous winters (Namias and Born, 1974).

\section{The California Coastal Shift}

Similarly, in our model analysis of the California Coastal region, the 6-mo period preceding the '76-'77 climate shift was influenced by persistent warming via the surface heat flux term in Eq. (1) combined with the strongest event (of the 1970-88 time interval) of warming by the horizontal advection term during fall 1976 and the subsequent winter. Taken together, these two effects produced a $10-15 \mathrm{~m}$ shallower mixed layer and more than half a degree warming in the surface temperature. After the abrupt shift, the anomalous state was maintained by reduced heat fluxes and somewhat weaker vertical mixing anomalies. Miller et al. (1994) give additional details of the thermodynamics in this region.

\section{Importance of the Transition of the Seasons}

For a longer term perspective on the seasonal variations of the heat budget, we inspected seasonal mean anomalies for the entire integration. This analysis (see Miller et al., 1994) indicates that the transition from fall (Sept.-Oct.-Nov.) to winter (Dec.-Jan.-Feb.) is key in the development of anomalous wintertime states. Strong cooling by advection and the surface heat flux term are clearly evident in the fall of 1976 in the MidPacific region. In the fall seasons before the shift the entrainment anomalies clearly exhibit a maintenance effect in anomalously warming the region and cooling it in the fall seasons after the shift. Although the winter heat budget anomalies do not exhibit any clear maintenance effects, the effect of the fall conditions is to promote an anomalously shallow Mid-Pacific mixed layer in the winters before the shift and a deeper mixed layer thereafter. The very deep mixed layer of the winter months then provides a long-term heat (or cold) storage reservoir for the ensuing seasons. To verify this 
post-shift deepening of the mid-Pacific mixedlayer depths and the presence of thermal memory from previous winters (as in Namias and Born, 1974), an observational analysis of mid-Pacific XBTs should be performed. M. Alexander and C. Deser (unpublished data, 1993) have recently commenced such a study and found some support for the Namias and Born hypothesis. Further study of our model simulation will help to determine the importance of long-term memory in the thermal field underlying the surface mixed layer.

\section{Summary and Remarks}

It therefore appears that the '76-' 77 shift in both the eastern and central North Pacific Ocean was caused by unique atmospheric anomalies, which acted over several months before the '76-'77 winter. The forcing of the ocean was organizéd over a basin scale (Fig. 1, a and b), such that a propensity for deeper Aleutian Lows in fall and winter produced large changes in the patterns of heat flux and ocean current advection. The combined result of this changed atmospheric state was an altered upper-ocean stratification and a basinwide SST shift. The changed heat flux pattern alone cannot entirely explain the SST shift in either the model or the observations, as is evident in the far western Pacific and in the positioning of the mid-Pacific SST cooling with respect to the heat flux shift in Figure 1. Ocean currents were found to be the important additional effect which caused the shift.

Although the strongly anomalous winter circulation of 1976-77 caused the shift, it appears that the oceanic climate regime in the Mid-Pacific was maintained (held in its anomalous state) after the shift by increased wind mixing acting upon a significantly cooler pool of water beneath the mixed layer. The warmer state after the shift along the California Coastal region, on the other hand, was maintained by reduced heat losses. This depiction of events is consistent with previous ocean modeling results by Haney (1980) for the September 1976 through January 1977 time interval, which showed that SST anomalies in the eastern and central North Pacific were predominantly due to anomalous heat fluxes and anomalous Ekman currents, respectively.

These results suggest other study directions besides those already mentioned. First, since this hindcast suggests that the midlatitude atmosphere drives the ocean into a new state, further numerical experiments with atmospheric models which explain why the '76-' 77 shift occurred in the North Pacific atmosphere itself will help to complete our understanding of the abrupt climate shift. Such studies may well indicate that tropical Pacific SST drives the midlatitude atmospheric response (Alexander, 1992). For example, Graham et al. (1994) describe an atmospheric general circulation model forced by anomalies of (1) only tropical SST, (2) only midlatitude SST and (3) global SST, which clearly shows that the deepened Aleutian Low over the North Pacific can be caused by tropical SST anomalies alone. However, it should be noted that if midlatitude oceanto-atmosphere feedback occurs in nature, its effect is implicit in the observed anomalous heat fluxes which drive our ocean model. Thus, though the atmosphere clearly drives the ocean in this simulation, midlatitude oceanic feedback to the atmosphere is not precluded by our results.

Second, analysis of the ocean model's gyrescale velocity and heat transport fields will help to clarify whether local Ekman dynamics and/or gyre-scale geostrophic circulation changes contributed significantly to establishing these persistent states in the midlatitude coupled ocean-atmosphere system (Trenberth, 1990). Third, the model also captures a warm shift in western tropical Pacific SST driven solely by the wind stress anomalies of the tropics, where the tropical heat flux anomalies in this model are parameterized to damp the model SST anomalies (cf. Graham, 1994). Thus at least some of the shift in tropical SST is a dynamic response (driven by ocean currents and/or wind stresses) rather than a direct thermodynamic response to anthropogenically forced warming of the tropical atmosphere (i.e., through surface heat fluxes). Last, the success of this hindcast is a testament to the usefulness of long-term surface marine observations, which have been the subject of some concern (Michaud and Lin, 1992).

A closing comment involves the semantic interpretation of what happened in the 1976-77 winter. Was it really a pronounced shift from one climate regime to another? Or was it simply part of a long-term climate variation, merely highlighted by a strongly anomalous winter? The huge horizontal advection anomalies, which occurred in the model hindcast, suggest that the 1976-77 winter was truly unique in that it apparently ended a multiyear warm regime in the model mid-Pacific Ocean's upper-ocean heat content. On the other hand, over the course of our 19-y simulation there are plenty of other sizable fluctuations in the oceanic thermal and velocity fields. Indeed, C. Deser (unpublished data, 1993) has analyzed central North Pacific expendable bathythermograph records for a similar time interval and found evidence for a more gradual change in upper-ocean heat content than suggested by our simulation. Furthermore, participants at a symposium on "Abrupt Changes in the Atmosphere-Ocean System in the Middle 1970's" held in 1991 at Kobe, Japan, reached agreement on interpreting the change as a decadal scale climate "variation" rather than a "shift" (A. Kitoh, personal communication, 1993). As highlighted in the Intergovernmental Oceanographic Commission's report (IOC, 1992) on oceanic interdecadal climate variability,
... the '76-'77 shift
. . . was caused by

unique atmospheric

anomalies, . . .

before the '76-'77

winter.

$\mathrm{O}_{\text {cean currents }}$

were found to be the

important additional

effect which caused

the shift. 
further monitoring, modeling, and deliberation is required to sort out properly this complicated and important subject.

\section{Acknowledgements}

Support was provided by NOAA Grants NA16RC0076-01 and NA90-AA-D-CP526, NASA Grant NAG5-236, the G. Unger Vetlesen Foundation and the University of California INCOR program for Global Climate Change. A.J.M. acknowledges the hospitality and support of the Institute of Geophysics and Planetary Physics of the Los Alamos National Laboratories while he was an Orson Anderson Visiting Scholar. Supercomputing resources were provided by the National Science Foundation through the National Center for Atmospheric Research and the San Diego Supercomputer Center. Reviews of the manuscript by Curt Ebbesmeyer, Akio Kitoh, an anonymous referee, and the editor were greatly appreciated. A.J.M. also thanks Clara Deser and Mike Alexander for additional comments and interesting discussions.

\section{References}

Alexander, M.A., 1992: Midlatitude atmosphere-ocean interaction during El Nino: Part I: The North Pacific Ocean, and Part II. The Northern Hemisphere atmosphere. $J$. Climate, 5, 944-972.

Cayan, D.R., A.J. Miller, T.P. Barnett, N.E. Graham, J.N. Ritchie and J.M. Oberhuber, 1994: Seasonal-interannual fluctuations in surface temperature over the Pacific: Effects of monthly winds and heat fluxes. In: Natural Climate Variability on Decade-to-Century Time Scales. D.G. Martinson et al., eds. National Academy of Sciences Press, Washington D.C.

and D.H. Peterson, 1989: The influence of North Pacific atmospheric circulation on streamflow in the West. Geophys. Monogr. 55, Am. Geophys. Union, 375-397.

Ebbesmeyer, C.C., D.R. Cayan, D.R. McLain, F.H. Nichols, D.H. Peterson and K.T. Redmond, 1991: 1976 step in the Pacific climate: Forty environmental changes between 1968-75 and 1977-1984. In: Proc. 7th Ann. Pacific Climate Workshop, Calif. Dept. of Water Resources, Interagency Ecol. Stud. Prog. Report 26.

Folland, C.K. and D.E. Parker, 1990: Observed variations of sea surface temperature. In: Climate-Ocean Interaction, M.E. Schlesinger, ed. Kluwer Academic Press, Dordrects, The Netherlands, 21-52.

Graham, N.E., 1994: Decadal scale variability in the 1970's and 1980's: Observations and model results. Clim. Dyn., 10, 60-70.
, T.P. Barnett, R. Wilde, M. Ponater and Silke Schubert, 1994: On the roles of tropical and mid-latitude SSTs in forcing interannual to interdecadal variability in the winter Northern Hemisphere circulation. J. Climate 7, 1500-1515.

Haney, R.L., 1980: A numerical case study of the development of large-scale thermal anomalies in the Central North Pacific Ocean. J. Phys. Oceanogr., 10, 541-556.

IOC, 1992: Oceanic Interdecadal Climate Variability. Intergovernmental Oceanographic Commission technical series No. 40, UNESCO, 40 pp.

Jones, P.D., T.M.L. Wigley and P.B. Wright, 1986: Global temperature variations between 1861 and 1984. Nature, $322,430-434$

Karl, T.R., 1988: Multi-year fluctuations of temperature and precipitation: the gray area of climate change. Climatic Change, 12, 179-197.

Kitoh, A., 1993: Decade-scale changes in the atmosphere-ocean system in the winter Northern Hemisphere. Umi to Sora (Sea and Sky), 68, 29-40. (in Japanese)

Levitus, S., 1982: Climatological Atlas of the World Ocean. U.S. Dept of Commerce, NOAA Professional Paper 13.

Luksch U. and H. von Storch, 1992: Modeling the low-frequency sea surface temperature variability in the North Pacific. J. Climate, 5, 893-906.

Michaud R. and C.A. Lin, 1992: Monthly summaries of merchant ship surface marine observations and implication for climate variability studies. Clim. Dyn., 7, 45-55.

Miller, A.J., 1992: Large-scale ocean-atmosphere interactions in a simplified coupled model of the midlatitude wintertime circulation. J. Atmos. Sci., 49, 273-286. , D.R. Cayan, T.P. Barnett, N.E. Graham, and J.M. Oberhuber, 1994: Interdecadal variability of the Pacific Ocean: model response to observed heat flux and wind stress anomalies. Clim. Dyn., 9, 287-302.

Namias, J. and R.M. Born, 1974: Further studies of temporal coherence in North Pacific sea surface temperature anomalies. J. Geophys. Res., 79, 797-798.

Oberhuber, J.M., 1993: Simulation of the Atlantic circulation with a coupled sea ice-mixed layer-isopycnal general circulation model. Part I: Model description. J. Phys. Oceanogr., 22, 808-829.

Polovina, J., G.T. Mitchum, N.E. Graham, M.P. Craig, E.E. DeMartini and E.N. Flint, 1994: Physical and biological consequences of a climatic event in the Central North Pacific. Fisheries Oceanogr., 3, 15-21.

Trenberth, K.E., 1990: Recent observed interdecadal climate changes in the Northern Hemisphere. Bull. Am. Meteorol. Soc., 71, 988-993.

and J.W. Hurrell, 1994: Decadal atmosphere-ocean variations in the Pacific. Clim. Dyn., 9, 303-319.

Venrick, E.L., J.A. McGowan, D.R. Cayan, and T.L. Hayward, 1987: Climate and chlorophyll a: long-term trends in the central North Pacific Ocean. Science, $238,70-72$.

Wunsch, C., 1992: Decade-to-century changes in the ocean circulation. Oceanography, 5, 99-106. 